\title{
Substrate Discrimination by ClpB and Hsp104
}

\author{
Danielle M. Johnston ${ }^{\ddagger \neq}$, Marika Miot ${ }^{\dagger \neq}$, Joel R. Hoskins ${ }^{\ddagger}$, Sue Wickner ${ }^{\star}$ and \\ Shannon M. Doyle *
}

Laboratory of Molecular Biology, National Cancer Institute, National Institutes of Health, Bethesda, MD, United States

\section{OPEN ACCESS}

Edited by:

Walid A. Houry,

University of Toronto, Canada

Reviewed by:

Peter Chien,

University of Massachusetts Amherst,

United States

Michal Zolkiewski,

Kansas State University, United States

*Correspondence:

Sue Wickner

wickners@mail.nih.gov

Shannon M. Doyle

doyles@mail.nih.gov

${ }^{\dagger}$ Present Address:

Danielle M. Johnston,

Bristol-Myers Squibb, Hopewell, NJ,

United States

Marika Miot,

UMR7622, Biologie du

Développement, Centre National de la

Recherche Scientifique, Institut de

Biologie Paris-Seine, UPMC University

Paris 06, Paris, France

${ }^{\ddagger}$ These authors have contributed equally to this work.

Specialty section:

This article was submitted to Protein Folding, Misfolding and Degradation

a section of the journal

Frontiers in Molecular Biosciences

Received: 30 March 2017 Accepted: 12 May 2017 Published: 29 May 2017

Citation:

Johnston DM, Miot M, Hoskins JR, Wickner S and Doyle SM (2017) Substrate Discrimination by C/pB and Hsp104. Front. Mol. Biosci. 4:36. doi: 10.3389/fmolb.2017.00036
ClpB of E. coli and yeast Hsp104 are homologous molecular chaperones and members of the AAA+ (ATPases Associated with various cellular Activities) superfamily of ATPases. They are required for thermotolerance and function in disaggregation and reactivation of aggregated proteins that form during severe stress conditions. ClpB and Hsp104 collaborate with the DnaK or Hsp70 chaperone system, respectively, to dissolve protein aggregates both in vivo and in vitro. In yeast, the propagation of prions depends upon Hsp104. Since protein aggregation and amyloid formation are associated with many diseases, including neurodegenerative diseases and cancer, understanding how disaggregases function is important. In this study, we have explored the innate substrate preferences of ClpB and Hsp104 in the absence of the DnaK and Hsp70 chaperone system. The results suggest that substrate specificity is determined by nucleotide binding domain-1.

Keywords: ClpB, Hsp104, molecular chaperone, disaggregase, DnaK, Hsp70, amyloid, aggregate

\section{INTRODUCTION}

All cells have a protein network involved in maintaining the proteome following periods of stress. Maintenance of the proteome utilizes energy-dependent molecular machines that facilitate protein remodeling, reactivation, disaggregation and degradation of misfolded, aggregated or inactive proteins. Members of the $\mathrm{Clp} / \mathrm{Hsp} 100$ family of ATP-dependent AAA+ proteins are molecular chaperones found in bacteria, archea, and the organelles of metazoans. Hsp104 and ClpB are two members of the $\mathrm{Clp} / \mathrm{Hsp} 100$ family and are found in yeast and bacteria, respectively, where they are essential for growth following extreme stress, such as high temperature (Hodson et al., 2012; Doyle et al., 2013; Mogk et al., 2015). They aid in cell survival by disaggregating and reactivating proteins inactivated and aggregated following stress conditions (Hodson et al., 2012; Doyle et al., 2013; Mogk et al., 2015). Under normal growth conditions, Hsp104 and ClpB are not essential, however Hsp104, is required for the propagation of specific amyloidogenic proteins, prions, in yeast (Romanova and Chernoff, 2009; Tuite et al., 2011; Wickner et al., 2011; Winkler et al., 2012). Protein disaggregation and reactivation by $\mathrm{Hsp} 104 / \mathrm{ClpB}$ require the collaboration of another molecular chaperone, Hsp70/DnaK and its cochaperones (Glover and Lindquist, 1998; Goloubinoff et al., 1999; Motohashi et al., 1999; Zolkiewski, 1999).

Hsp104 and $\mathrm{ClpB}$, like other $\mathrm{Clp} / \mathrm{Hsp} 100$ chaperones are hexameric ring-like structures (Diemand and Lupas, 2006; Erzberger and Berger, 2006; Doyle et al., 2013; Mogk et al., 2015). Recent studies have indicated that the Hsp104 hexamer may take on a spiral conformation at some point during the protein disaggregation process (Heuck et al., 2016; Yokom et al., 2016). Spirals have been observed previously when ClpA and ClpB were crystalized (Guo et al., 2002; Lee et al., 2003), however the importance of a spiral vs. closed ring architecture is not yet understood. 
Each protomer of the Hsp104/ClpB hexamer contains two highly conserved AAA + modules, nucleotide binding domain-1 and -2 (NBD-1 and NBD-2), with each NBD possessing a Walker A and Walker B motif, an arginine finger motif and sensor-1 and -2 motifs (Hanson and Whiteheart, 2005; Erzberger and Berger, 2006; Wendler et al., 2012; Doyle et al., 2013; Figures 1A,B). The Hsp104/ClpB protomer also contains an N-terminal domain (N-domain, NTD), which is less conserved between species than the nucleotide binding domains. The NTD is connected to NBD-1 via a flexible linker and is important for interaction with some substrates (Lee et al., 2003; Nagy et al., 2010; Doyle et al., 2012; Zhang et al., 2012; Rosenzweig et al., 2015; Sweeny et al., 2015). Finally, a coiled-coil middle domain (M-domain), which is required for disaggregation activity, is inserted within NBD-1 of Hsp104/ClpB (Lee et al., 2003, 2007, 2010; Doyle et al., 2013; Mogk et al., 2015). The M-domain of Hsp104 and $\mathrm{ClpB}$ has been shown to directly interact with the Hsp70 chaperone, Ssal in yeast and DnaK in bacteria, in a speciesspecific manner (Sielaff and Tsai, 2010; Miot et al., 2011; Seyffer et al., 2012; Rosenzweig et al., 2013; Kummer et al., 2016). This direct interaction and collaboration is required for the synergy observed in ATP hydrolysis and substrate disaggregation (Doyle et al., 2007a; Miot et al., 2011; Seyffer et al., 2012; Rosenzweig et al., 2013; Kummer et al., 2016). Additionally, Hsp104 has a Cterminal domain that is involved in hexamerization and may play a role in thermotolerance (Mackay et al., 2008).

Although $\mathrm{ClpB}$ and $\mathrm{Hsp} 104$ require the DnaK/Hsp70 chaperone system for protein disaggregation in vivo and in vitro, alone they possess intrinsic protein remodeling activities: including protein unfolding, activation and disaggregation of small aggregates (Doyle et al., 2007b). The intrinsic chaperone activity is evoked by using mixtures of ATP and ATP $\gamma S$ or by
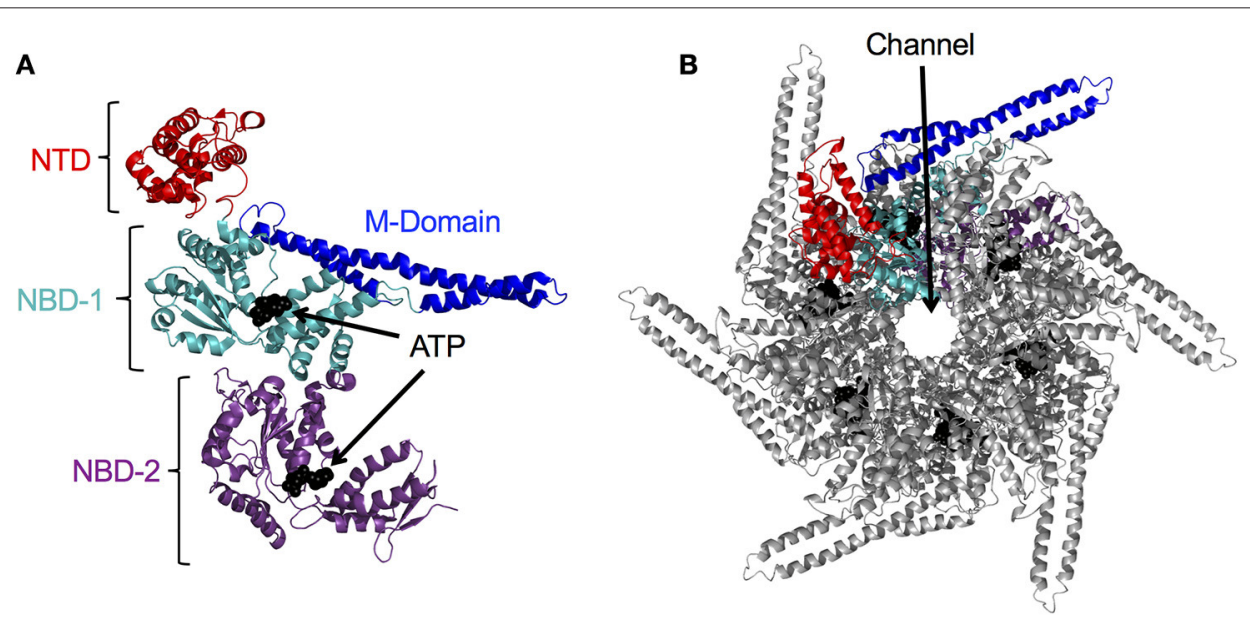

C GFP-38 disaggregation

D
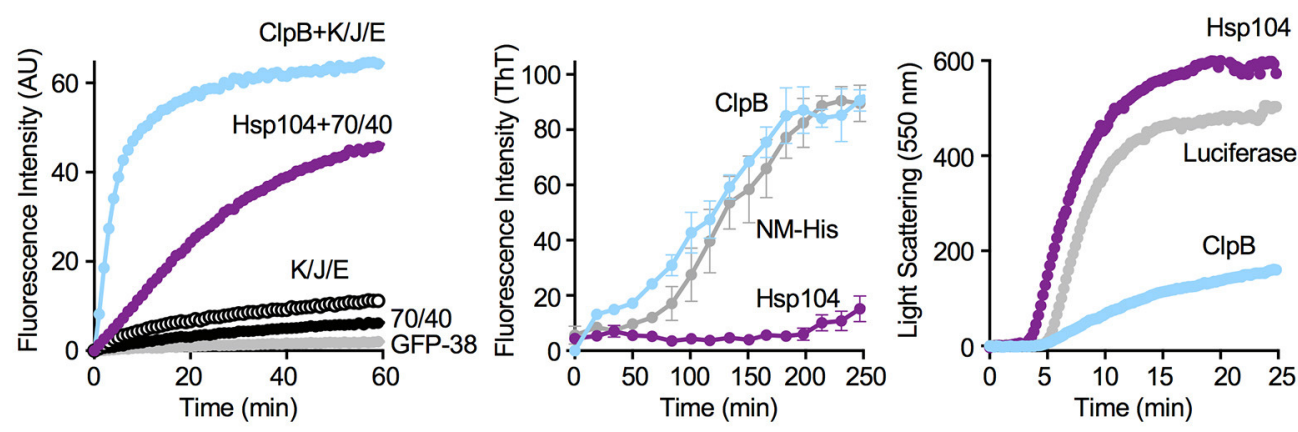

FIGURE 1 | Hsp104 and ClpB have multiple chaperone activities in vitro. (A) Structure of the ClpB monomer from Thermus thermophilus bound to AMP-PNP (PDB code: 1QVR; chain C) is shown (Lee et al., 2003). Each monomer is comprised of an amino-terminal domain (N-domain; NTD; red), a coiled-coil middle domain (M-domain; blue) and two nucleotide-binding domains (NBD-1 and NBD-2; cyan and purple, respectively). The nucleotide is shown as a CPK model in black. (B) T. thermophilus ClpB hexamer model with bound ATP is shown (Lee et al., 2003; Diemand and Lupas, 2006). In (B), one monomer of the hexamer is shown in color as described in (A). (C) Hsp104 and ClpB can collaborate with the Hsp70 or DnaK system, respectively, in GFP-38 disaggregation, as observed by monitoring the increase in GFP fluorescence over time as described in Section Materials and Methods. (D) Hsp104, but not ClpB, can prevent the assembly of NM-His into amyloid fibers, as observed by monitoring Thioflavin T (ThT) fluorescence as described in Section Materials and Methods. Data are means \pm SEM ( $n=3)$. (E) ClpB, but not Hsp104, can prevent the aggregation of heat-denatured luciferase as observed by measuring turbidity by $90^{\circ}$ light scattering as described in Section Materials and Methods. In (C,E) a representative experiment of three or more replicates is shown. 
using ATP hydrolysis defective ClpB/Hsp104 mutant proteins (Doyle et al., 2007b; Hoskins et al., 2009). One interpretation of the observations is that these conditions slow ATP hydrolysis by the chaperone allowing both substrate binding, a condition that requires ATP binding but not hydrolysis, and substrate translocation, a process that requires ATP hydrolysis, to occur simultaneously. By studying ClpB and Hsp104 using these conditions, ClpB and Hsp104 have been shown to function similarly to other Clp/Hsp100 chaperones. Briefly, Clp/Hsp100 chaperones recognize polypeptide substrates that contain an unstructured region of a minimum length, generally at an end. This unstructured region is engaged by residues in pore loops, which extend into the central channel of the Clp/Hsp100 hexamer (Baker and Sauer, 2012; Doyle et al., 2013; Mogk et al., 2015). These pore loops are in a nucleotide binding domain and use ATP driven conformational cycles to power mechanical unfolding of the polypeptide and translocation of the unfolded polypeptide through the channel (Weber-Ban et al., 1999; Lum et al., 2004, 2008; Schlieker et al., 2004; Siddiqui et al., 2004; Weibezahn et al., 2004; Hinnerwisch et al., 2005; Martin et al., 2008; Tessarz et al., 2008; Doyle et al., 2013). Unfolded substrate is then released and can refold spontaneously or with the help of additional chaperones (Hodson et al., 2012; Zolkiewski et al., 2012; Doyle et al., 2013; Mogk et al., 2015).

Substrate recognition and binding by $\mathrm{Clp} / \mathrm{Hsp} 100$ chaperones, has been well-studied for many Clp proteins, including ClpA and ClpX, two bacterial chaperones associated with proteases (Weber-Ban et al., 1999; Zolkiewski, 2006; Baker and Sauer, 2012). Specific substrates have been identified by proteomic studies and specific recognition sequences have been determined (Flynn et al., 2003; Zolkiewski, 2006; Baker and Sauer, 2012). For ClpB and Hsp104 however, few specific substrates have been identified, and a mechanism for substrate discrimination by $\mathrm{ClpB}$ and Hsp104 has not been described. In the present study, we have further explored the question of substrate recognition by $\mathrm{ClpB}$ and Hsp104.

\section{MATERIALS AND METHODS}

\section{Plasmids}

pNM-His was constructed by amplifying the NM region of sup35 by PCR using $5^{\prime}$ and $3^{\prime}$ oligos containing Nde1 and BamHI sites, respectively, and pJC25NMstop (Addgene, plasmid \#1228, Shorter and Lindquist, 2004) as template. The NM region PCR product does not contain a stop codon. This DNA was digested with Nde1 and BamHI and ligated into similarly digested pET24b. The resulting plasmid was digested with EcoR1 and Eag1 and a linker coding for six-histidines followed by a stop codon was ligated between the sites. The plasmid was confirmed by DNA sequencing.

\section{Purification of Proteins}

GroEL $_{\text {Trap }}$ (Weber-Ban et al., 1999), Hsp104-ClpB chimeras (Miot et al., 2011), GFP-15 (Hoskins et al., 2002), GFP-38 and GFP- $\mathrm{X}_{\mathrm{X}}-\mathrm{H}_{6}$ proteins (Hoskins and Wickner, 2006), and GFP (Hoskins et al., 2000) were purified as previously described. Luciferase was from Promega. Protein concentrations given are for monomeric GFP fusion proteins, NM-His and luciferase, hexameric ClpB, Hsp104 and chimeras, and tetradecameric GroEL $L_{\text {Trap }}$.

\section{ClpB Purification}

ClpB wild-type and ClpB E279A,E678A (Weibezahn et al., 2003; Doyle et al., 2007b) were constructed and purified as previously described (Zolkiewski, 1999), but with modifications. Cultures of E. coli BL21(DE3) containing pClpBwt (pET24b vector)

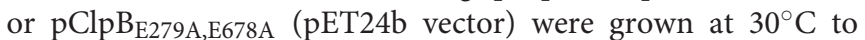
$\mathrm{OD}_{600}$ of $\sim 0.6$ and then induced overnight with $0.1 \mathrm{mM}$ IPTG. All purification steps were carried out at $4^{\circ} \mathrm{C}$. Clarified cellular extracts were purified over a Q-Sepharose column (GE Healthcare) in $20 \mathrm{mM}$ Tris- $\mathrm{HCl}, \mathrm{pH} 7.5,80 \mathrm{mM} \mathrm{NaCl}, 5 \mathrm{mM}$ $\mathrm{MgCl}_{2}, 0.5 \mathrm{mM}$ EDTA, 20\% glycerol (vol/vol) and $1 \mathrm{mM} \mathrm{DTT}$. Proteins were eluted from the column with a linear gradient of $80-1,000 \mathrm{mM} \mathrm{NaCl}$ in the same buffer. Fractions containing ClpB were further purified using Sephacryl S-200 chromatography in $50 \mathrm{mM}$ Tris- $\mathrm{HCl}, \mathrm{pH}$ 7.5, $200 \mathrm{mM} \mathrm{KCl}, 10 \%$ glycerol, $20 \mathrm{mM}$ $\mathrm{MgCl}_{2}, 1 \mathrm{mM}$ EDTA, and $1 \mathrm{mM}$ DTT.

\section{Hsp104 Purification}

Hsp104 wild-type and Hsp104E285A, E687A (Bosl et al., 2005) were constructed and purified as previously described, but with minor modifications (Miot et al., 2011). This is a detailed description of our Hsp104 purification protocol. The plasmid pHsp104wt was used for the expression of tag-less, wild-type Hsp104 (Miot et al., 2011). pHsp104wt was transformed into E. coli strain Rosetta(DE3) by electroporation. Transformed cells were plated on LB plates supplemented with $50 \mu \mathrm{g} / \mathrm{mL}$ ampicillin and $10 \mu \mathrm{g} / \mathrm{mL}$ chloramphenicol and grown overnight at $32^{\circ} \mathrm{C}$. Transformations were optimized to yield several hundred colony-forming units on each plate. The fresh transformants were used to inoculate Hsp104 expression cultures as follows: $5 \mathrm{~mL}$ of LB broth was added to each plate and the cells were resuspended using a sterile glass or plastic rod; cells from a single plate were used to inoculate $1 \mathrm{~L}$ of LB broth supplemented with $100 \mu \mathrm{g} / \mathrm{mL}$ carbenicillin (chloramphenicol was not added) in a $2 \mathrm{~L}$ baffled flask. Typically, 2-4 L of culture were grown at the same time for one preparation. The cultures were incubated with shaking at $25^{\circ} \mathrm{C}$ and $250 \mathrm{rpm}$ to an $\mathrm{OD}_{600}=0.25$; the incubator temperature was reduced to $18^{\circ} \mathrm{C}$ and $\mathrm{Hsp} 104$ expression induced with the addition of IPTG to a final concentration of $0.1 \mathrm{mM}$; growth was continued overnight $(14-16 \mathrm{~h})$ at $18^{\circ} \mathrm{C}$ with shaking at $250 \mathrm{rpm}$. Cells were harvested by centrifugation in a pre-chilled rotor at 5,000 $\times \mathrm{g}(\sim 5,000 \mathrm{rpm}$ in a Sorvall SLA3000 or equivalent) for $10 \mathrm{~min}$ at $4^{\circ} \mathrm{C}$. The cell pellet from each $1 \mathrm{~L}$ culture was resuspended in $25 \mathrm{~mL}$ ice cold Q104 buffer [ 40 mM Hepes pH 7.5, $80 \mathrm{mM} \mathrm{NaCl}, 0.5 \mathrm{mM}$ EDTA, $20 \mathrm{mM} \mathrm{MgCl}_{2}$, $1 \mathrm{mM}$ DTT, 20\% glycerol (vol/vol), $5 \mathrm{mM} \mathrm{ATP]} \mathrm{containing}$ EDTA-free complete protease inhibitor cocktail (Roche), which was prepared by mixing 1 tablet/50 mL of Q104 buffer. The resuspended cells were lysed by two or three passages through an ice-cold French Pressure cell (10,000 psi). The cell lysate was collected at the sample outlet tube with a vessel submerged in an ice bath. Cell debris was removed by centrifugation at $12,000 \times \mathrm{g}$ $\left(10,000 \mathrm{rpm}\right.$ in a Sorvall SS-34 or equivalent) for $15 \mathrm{~min}$ at $4^{\circ} \mathrm{C}$. 
The resulting supernatant was then centrifuged at $130,000 \times \mathrm{g}$ $(35,000 \mathrm{rpm}$ in a Sorvall F50L-8x39 or equivalent) for $30 \mathrm{~min}$ at $4{ }^{\circ} \mathrm{C}$. As an alternative, a single centrifugation step at 34,500 $\times \mathrm{g}(17,000 \mathrm{rpm}$ in a Sorvall SS-34 or equivalent) for $90 \mathrm{~min}$ at $4{ }^{\circ} \mathrm{C}$ will produce similar results. The supernatant was used for subsequent purification. The supernatant must be subjected to the first column purification step without interruption or overnight storage or Hsp104 activity will be significantly reduced or lost. All purification steps were performed at $4{ }^{\circ} \mathrm{C}$ using prechilled buffers. The clarified lysate was applied to a $20 \mathrm{~mL}$ Qsepharose Fast Flow (GE Healthcare) column equilibrated with Q104 buffer at $1 \mathrm{~mL} / \mathrm{min}$ using a peristaltic pump. The column was washed with two column volumes of Q104 buffer and protein was eluted with a $100 \mathrm{~mL}, 80-500 \mathrm{mM} \mathrm{NaCl}$ linear gradient in Q104 buffer. Column fractions of $3 \mathrm{~mL}$ each were collected. At this point, fractions containing $\mathrm{Hsp} 104$ can be stored at $-80^{\circ} \mathrm{C}$. Next, a $3 \mathrm{~mL}$ Q-sepharose Hsp104 peak fraction was applied onto a $40 \mathrm{~mL}$ Sephacryl S-200 High Resolution (GE Healthcare) column $(1.5 \mathrm{~cm}$ I.D. $\times 30 \mathrm{~cm}$ length) equilibrated with SE104 buffer (20 mM Hepes pH 7.5, $200 \mathrm{mM} \mathrm{KCl,} 0.5$ mM EDTA, 20 $\mathrm{mM} \mathrm{MgCl}_{2}, 1 \mathrm{mM}$ DTT, $20 \%$ glycerol (vol/vol), $5 \mathrm{mM} \mathrm{ATP)}$ at $0.5 \mathrm{~mL} / \mathrm{min}$ using a peristaltic pump. Fractions $(1 \mathrm{~mL})$ were collected and those containing purified Hsp104 were stored at $-80^{\circ} \mathrm{C}$. When thawed for use, individual fractions are divided into $100-200 \mu \mathrm{L}$ aliquots and stored at $-80^{\circ} \mathrm{C}$ to minimize the number of freeze-thaw cycles. Using this procedure, the Hsp104 activity is stable for at least 1 year.

\section{NM-His Purification}

NM-His was purified as previously described (Glover et al., $1997)$ with modifications. Cultures (50-100 mL) of BL21(DE3) $c l p P$ - transformed with pNM-His were grown in LB $(30 \mu \mathrm{g} / \mathrm{mL}$ Kan and $10 \mu \mathrm{g} / \mathrm{mL} \mathrm{Cam}$ ) at $37^{\circ} \mathrm{C}$ to an $\mathrm{OD}_{600}$ of $\sim 0.6-0.8$ and induced with $1 \mathrm{mM}$ IPTG for $2 \mathrm{~h}$. Cells were harvested by centrifugation and resuspended in $40 \mathrm{mM}$ Hepes, $\mathrm{pH} 7.4$, and lysed using a French Press. Urea was added to a final concentration of $8 \mathrm{M}$ and the lysate kept at room temperature $\left(\sim 23^{\circ} \mathrm{C}\right)$ for the remaining preparation. Insoluble material was removed by centrifugation. NM-His was precipitated with the addition of $\mathrm{MeOH}$ to $70 \%$ ( $\mathrm{vol} / \mathrm{vol}$ ) and the precipitate collected by centrifugation. The protein pellet was resuspended in NM Buffer (40 mM HEPES, pH 7.4, 8 M Urea) and then incubated with TALON resin for $30 \mathrm{~min}$. The slurry was poured into an empty chromatography column and washed with 10 bed volumes of NM Buffer. NM-His was eluted with NM Buffer containing 50 $\mathrm{mM}$ Imidazole. NM-His containing fractions were precipitated with $\mathrm{MeOH}$ as above, the pellet was resuspended in $70 \% \mathrm{MeOH}$ and the sample was stored at $-80^{\circ} \mathrm{C}$ in small aliquots. NM-His was stable for $\sim 6$ months.

\section{GFP Unfolding Assay}

Reaction mixtures $(100 \mu \mathrm{L})$ contained buffer A [20 mM Tris$\mathrm{HCl}, \mathrm{pH}$ 7.5, $100 \mathrm{mM} \mathrm{KCl}, 5 \mathrm{mM}$ DTT, $0.1 \mathrm{mM}$ EDTA, and 10\% glycerol (vol/vol)], 0.005\% Triton X-100 (vol/vol), $0.2 \mathrm{mg} / \mathrm{mL}$ BSA, $10 \mathrm{mM} \mathrm{MgCl}_{2}, 2 \mathrm{mM}$ ATP, and $2 \mathrm{mM} \mathrm{ATP} \gamma \mathrm{S}$ (Roche), an ATP regenerating system $(20 \mathrm{mM}$ creatine phosphate and $6 \mu \mathrm{g}$ creatine kinase), $0.4 \mu \mathrm{M}$ GFP or GFP fusion protein, $3.0 \mu \mathrm{M}$
GroEL $_{\text {Trap }}$ and $1 \mu \mathrm{M} \mathrm{ClpB}$ or Hsp104. GroEL $L_{\text {Trap }}$ is a mutant form of GroEL that binds but does not release unfolded proteins and was included in the reactions to prevent the GFP fusion proteins from refolding (Weber-Ban et al., 1999). Unfolding was initiated with the addition of ATP, ATP $\gamma \mathrm{S}$, and $\mathrm{MgCl}_{2}$ and the change in fluorescence signal was monitored over time at $25^{\circ} \mathrm{C}$ using a Tecan Infinite M200Pro plate reader. Excitation and emission wavelengths were 395 and $510 \mathrm{~nm}$, respectively. For $\mathrm{K}_{\mathrm{M}}$ and $\mathrm{V}_{\max }$ determinations, substrate concentrations were varied between 0.1 and $10 \mu \mathrm{M}$ while keeping $\mathrm{ClpB}$ and Hsp104 concentrations constant at $1 \mu \mathrm{M}$. GroEL Trap was varied between 1 and $5 \mu \mathrm{M}$ depending on the substrate concentration. Unfolding rates were determined from the initial linear decrease in fluorescence intensities of the GFP fusion proteins. MichaelisMenten analysis was performed using the non-linear regression analysis in Prism 7.0a for Mac OS X, GraphPad Software, La Jolla California USA (http://www.graphpad.com).

\section{Protein Complexes}

Reaction mixtures $(100 \mu \mathrm{L})$ containing GFP-15, GFP-X $\mathrm{X}_{30}-\mathrm{H}_{6}$,

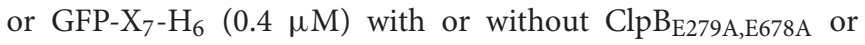
Hsp104 ${ }_{\mathrm{E} 285 \mathrm{~A}}$, E687A $(2 \mu \mathrm{M})$ were incubated in buffer A, $0.005 \%$ Triton-X100, $5 \mathrm{mM}$ ATP, and $10 \mathrm{mM} \mathrm{MgCl}_{2}$ for $45 \mathrm{~min}$ at room temperature. Reaction mixtures were fractionated on a Sephacryl S200 column (GE Healthcare) equilibrated with $20 \mathrm{mM}$ Tris$\mathrm{HCl}, \mathrm{pH}$ 7.5, $100 \mathrm{mM} \mathrm{NaCl}, 20 \mathrm{mM} \mathrm{KCl}, 0.1 \mathrm{mM}$ EDTA, 10\% glycerol, $5 \mathrm{mM}$ ATP, and $10 \mathrm{mM} \mathrm{MgCl}_{2}$ at room temperature. Fractions $(100 \mu \mathrm{L})$ were collected and GFP fluorescence was measured in a Tecan Infinite M200Pro plate reader at $25^{\circ} \mathrm{C}$ as described above. The percentage of the GFP fusion protein signal that was shifted upon chaperone binding was determined by calculating the area under the shifted peak compared to the total area under all peaks. The elution profile of $\mathrm{ClpB}_{\mathrm{E} 279 \mathrm{~A}, \mathrm{E} 678 \mathrm{~A} \text { or }}$ Hsp104 2 285A,E687A $(2 \mu \mathrm{M})$ was determined in the absence of GFP fusion protein by measuring protein in each fraction using the Bradford assay.

\section{Prevention of Heat-Denatured Luciferase Aggregation}

Luciferase $(0.2 \mu \mathrm{M})$ was denatured at $42^{\circ} \mathrm{C}$ in Buffer B (50 $\mathrm{mM}$ Tris- $\mathrm{HCl}, \mathrm{pH} 7.5,150 \mathrm{mM} \mathrm{KCl}, 20 \mathrm{mM} \mathrm{MgCl}_{2}, 2 \mathrm{mM}$ $\mathrm{DTT}$ ) with $5 \mathrm{mM} \mathrm{ATP} \gamma \mathrm{S}$ in the presence or absence of 0.5 $\mu \mathrm{M}$ ClpB or Hsp104 as previously described (Weibezahn et al., 2003). Aggregation of luciferase was monitored as an increase in sample turbidity by measuring $90^{\circ}$ static light scattering on a PerkinElmer LS55 luminescence spectrometer with excitation and emission wavelengths each set to $550 \mathrm{~nm}$.

\section{Prevention of NM-His Fiber Assembly}

NM-His fiber assembly reactions $(100 \mu \mathrm{L})$ were initiated by diluting denatured NM-His in $8 \mathrm{M}$ urea $(20 \mathrm{mM}$ Tris- $\mathrm{HCl}$, pH7.4) 100-fold to a final concentration of $0.2 \mu \mathrm{M}$ with assembly buffer (40 mM Hepes-KOH, pH 7.4, 150 mM KCl, 1 mM DTT) in the presence or absence of $0.5 \mu \mathrm{M} \mathrm{ClpB}$ or Hsp104 (Shorter and Lindquist, 2004). Assembly reactions were agitated at 1,000 rpm and assembly of NM-His fibers was assessed by Thioflavin T (ThT) binding (100 $\mu \mathrm{M}$ final concentration). ThT fluorescence 
was read in a Tecan Infinite M200Pro plate reader at $25^{\circ} \mathrm{C}$ using excitation and emission wavelengths of 440 and $481 \mathrm{~nm}$, respectively.

\section{GFP-38 Disaggregation Assay}

GFP-38 disaggregation was performed as previously described (Miot et al., 2011). Reaction mixtures $(100 \mu \mathrm{L})$ contained $25 \mathrm{mM}$ Hepes, pH 7.5, $50 \mathrm{mM} \mathrm{KCl,} 0.1 \mathrm{mM}$ EDTA, 5 mM DTT, 0.005\% Triton-X-100 (vol/vol), 4 mM ATP, an ATP regenerating system (10 $\mathrm{mM}$ creatine phosphate and $3 \mu \mathrm{g}$ creatine kinase), $10 \mathrm{mM}$ $\mathrm{MgCl}_{2}, 5 \mu \mathrm{L}$ heat-aggregated GFP-38 (prepared by heating 75$100 \mu \mathrm{L}$ of $14 \mu \mathrm{M}$ GFP-38 for $15 \mathrm{~min}$ at $80^{\circ} \mathrm{C}$ in $0.2 \mathrm{~mL}$ PCR tubes; the heated luciferase was rapidly frozen on dry ice, thawed and used immediately), $0.5 \mu \mathrm{M}$ ClpB, $1.3 \mu \mathrm{M}$ DnaK, $0.2 \mu \mathrm{M}$ DnaJ and $0.1 \mu \mathrm{M}$ GrpE or $0.5 \mu \mathrm{M}$ Hsp104, $1.3 \mu \mathrm{M}$ human Hsp70 (HSPA1A) and $0.2 \mu \mathrm{M}$ Ydj1. GFP fluorescence was monitored over time at $23^{\circ} \mathrm{C}$ using a Varian Cary Eclipse fluorescence spectrophotometer with a plate reader. Excitation and emission wavelengths were 395 and $510 \mathrm{~nm}$, respectively. Reactivation was determined compared to a non-denatured GFP-38 control.

\section{RESULTS}

\section{Hsp104 and ClpB Exhibit Substrate Preferences}

In this work, we wanted to know if ClpB and Hsp104 differ in their innate substrate preferences. The experiments addressing this question were performed in the absence of the DnaK or Hsp70 chaperone so it would be possible to study the basic properties of the $\mathrm{ClpB} / \mathrm{Hsp} 104$ machine and avoid the complication of substrate recognition by DnaK and Hsp70. However, it is known that in vivo and in vitro in the presence of ATP, both $\mathrm{ClpB}$ and Hsp104 require DnaK/Hsp70 to carry out protein disaggregation and reactivation (Glover and Lindquist, 1998; Goloubinoff et al., 1999; Motohashi et al., 1999; Zolkiewski, 1999; Doyle et al., 2013).

For these experiments, we used $\mathrm{ClpB}$ that was purified as described previously (Zolkiewski, 1999; Doyle et al., 2015; see Section Materials and Methods) and Hsp104 that was purified using standard biochemical protocols described in detail in Section Materials and Methods. The chaperones were isolated from E. coli cells overexpressing untagged ClpB or Hsp104 and consequently Hsp104 might not contain post translational modifications that would be present when the protein is expressed in yeast. Biochemical properties of Hsp104 were determined because controversy exists in the literature regarding several of the reported activities of Hsp104. Hsp104 isolated as described here reactivated aggregates in the presence of ATP in combination with Hsp70 and Hsp40 (Figure 1C; either yeast Ssa1 or human Hsp70 functioned in combination with Ydj1 or Sis1 from yeast; Miot et al., 2011; Reidy et al., 2014; Doyle et al., 2015). Additionally, it prevented amyloid assembly in the absence of ATP and Hsp70 (Figure 1D; Inoue et al., 2004; Shorter and Lindquist, 2004, 2006), and as previously observed it was unable to prevent aggregation of heat-denatured luciferase (Figure 1E; Glover and Lindquist, 1998). It also hydrolyzed ATP at a rate similar to published rates (Lum et al., 2004; Doyle et al., 2007b;
Miot et al., 2011) and unfolded substrates using a condition that elicits the innate chaperone activity of Hsp104, a mixture of ATP and ATP $\gamma$ S (Figure 2; Doyle et al., 2007b). However, using Hsp104 prepared as described here, we were unable to repeat the observations, including one from our group, that Hsp104 accelerates assembly of the NM fragment of Sup35 in an ATP-dependent reaction (Shorter and Lindquist, 2004, 2006; Doyle et al., 2007b) and promotes disassembly of NM fibers in an ATP-dependent reaction in the absence of Hsp70 (Shorter and Lindquist, 2004, 2006; Doyle et al., 2007b; DeSantis et al., 2012). Other groups have previously reported that their Hsp104 preparations were unable to perform these two reported activities (Inoue et al., 2004; Krzewska and Melki, 2006; Savistchenko et al., 2008; Glover and Lum, 2009; Kummer et al., 2016).

To explore substrate discrimination by ClpB and Hsp104 in the absence of DnaK/Hsp70 we tested the two chaperones for the ability to act on several model substrates in vitro. The innate protein unfolding activity of $\mathrm{ClpB}$ and Hsp104 in the absence of the Hsp70/DnaK chaperone system was measured in the presence of a mixture of ATP and ATP $\gamma \mathrm{S}$ to elicit the intrinsic chaperone activity (Doyle et al., 2007b, 2012; Hoskins et al., 2009). GFP-15, a GFP fusion protein containing a C-terminal 15-amino acid peptide was used as a model substrate. We had previously demonstrated that GFP-15 is a substrate for ClpA, but not ClpX (Hoskins et al., 2002), and we had also shown that $\mathrm{ClpB}$ catalyzes its unfolding in the presence of mixtures of ATP and ATP $\gamma$ S (Hoskins et al., 2009; Doyle et al., 2012; Table 1; Figure 2A). Unfolding of GFP-15 was determined by monitoring the decrease in GFP fluorescence over time in the presence of GroEL $_{\text {Trap }}$, a mutant form of GroEL that binds and does not release unfolded proteins (Figure 2A; Weber-Ban et al., 1999). In contrast to the rapid rate of GFP-15 unfolding seen with $\mathrm{ClpB}$, the rate of unfolding by $\mathrm{Hsp} 104$ was $\sim 10$-fold slower (Figure 2B). We next tested another GFP fusion protein that was previously shown to be a substrate for unfolding by ClpA, but not ClpX, GFP- $\mathrm{X}_{30}-\mathrm{H}_{6}$, which contains a C-terminal 30 amino acid peptide followed by a six-histidine tag (Hoskins and Wickner, 2006; Table 1; Figures 2A,B). ClpB unfolded GFP- $\mathrm{X}_{30}-\mathrm{H}_{6}$ at a much slower rate than it did GFP-15 (Figure 2A), however Hsp104 catalyzed unfolding of this substrate at a rate $\sim 5$-fold faster than $\mathrm{ClpB}$ (Figure 2B), showing that ClpB and Hsp104 differ in their ability to act on these substrates.

We then wanted to know if $\mathrm{ClpB}$ and Hsp104 also differed in their ability to recognize and unfold GFP proteins with other polypeptide tags fused at either the $\mathrm{N}$ - or C-terminus. When two N-terminally tagged GFP fusion proteins, 15-GFP with the same 15 amino acid tag as on GFP-15 and 1-24 $\beta$ GalGFP with a tag comprised of the first 24 amino acids of $\beta$ galactosidase, were tested, both substrates were unfolded by $\mathrm{ClpB}$, as previously observed (Doyle et al., 2012; Table 1; Figure 2C). In contrast, neither of the $\mathrm{N}$-terminally tagged substrates tested was detectably unfolded by Hsp104 (Figure 2D), supporting the above suggestion that $\mathrm{ClpB}$ and Hsp104 differ in their ability to unfold specific substrates. We next tested two additional Cterminally tagged GFP fusion proteins of different length but similar sequence, GFP- $\mathrm{X}_{42}-\mathrm{H}_{5}$ and GFP- $\mathrm{X}_{7}-\mathrm{H}_{6}$, which are related to GFP-X $\mathrm{X}_{30}-\mathrm{H}_{6}$ (Table 1). Similar to the results observed for 

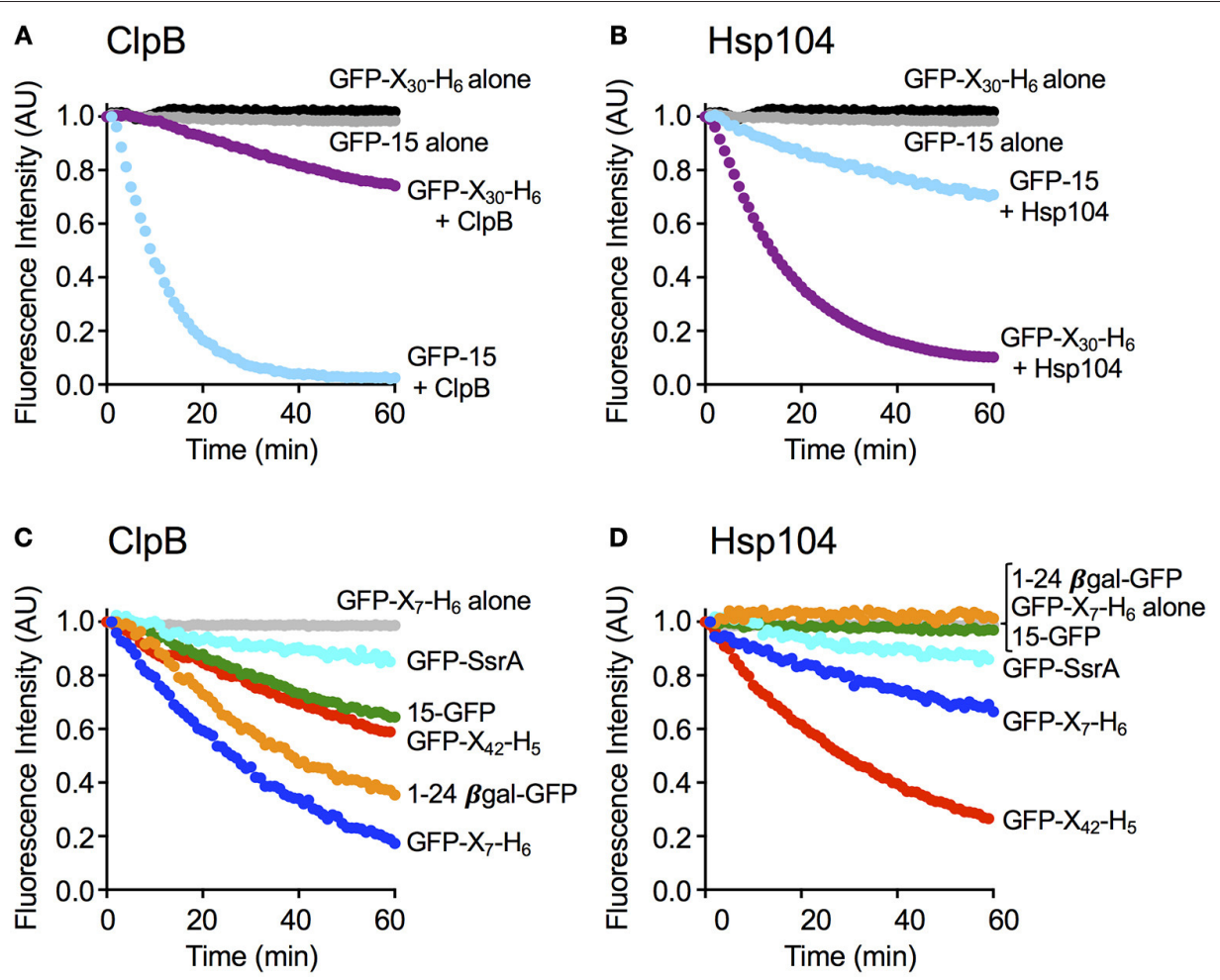

FIGURE 2 | ClpB and Hsp104 exhibit specificity for substrate in unfolding reactions. (A) ClpB or (B) Hsp104 mediated unfolding of GFP-15 or GFP-X $\mathrm{X}_{30}-\mathrm{H}_{6}$ in the presence of ATP and ATP $\gamma$ S as described in Section Materials and Methods. ClpB (C) or Hsp104 (D) mediated unfolding of additional GFP model substrates, GFP-SsrA, 15-GFP, GFP-X $42-H_{5}, 1-24$ Bgal-GFP, and GFP-X $7-H_{6}$, in the presence of ATP and ATP $\gamma$ S. In (A-D), the initial fluorescence was set equal to 1 and a data set representative of three or more replicates is shown. Substrates used in (A-D) are described in Table 1.

TABLE 1 | GFP fusion proteins.

\begin{tabular}{|c|c|c|c|}
\hline Name & Tag location & Tag length & Tag sequence \\
\hline GFP-15a & C-terminus & 15 & MNQSFISDILYADIE \\
\hline 15-GFP & $\mathrm{N}$-terminus & 15 & MNQSFISDILYADIE \\
\hline GFP-SsrA & C-terminus & 11 & AANDENYALAA \\
\hline 1-24ßGal-GFPb & $\mathrm{N}$-terminus & 24 & $\begin{array}{l}\text { MTMITDSLAVVLQRRDWEN } \\
\text { PGVTQ }\end{array}$ \\
\hline $\mathrm{GFP}-\mathrm{X}_{7}-\mathrm{H}_{6}^{\mathrm{C}}$ & C-terminus & 13 & KLAAALEHHHHHH \\
\hline GFP- $X_{30}-\mathrm{H}_{6}$ & C-terminus & 36 & $\begin{array}{l}\text { AVHMASMTGGNNMGRDPN } \\
\text { SSSVDKLAAALEHHHHHH }\end{array}$ \\
\hline GFP-X $\mathrm{X}_{42}-\mathrm{H}_{5}$ & C-terminus & 47 & $\begin{array}{l}\text { PMFAYSESDLIDAVHMASMTGG } \\
\text { NNMGRDPNSSSVDKLAAALE } \\
\text { HHHHH }\end{array}$ \\
\hline
\end{tabular}

aThe 15 amino acid tag on GFP-15 and 15-GFP comprises the first $15 \mathrm{~N}$-terminal residues of the P1 plasmid replication initiator protein, RepA (Hoskins et al., 2002).

${ }^{b}$ The 24 amino acid tag on 1-24 $\beta$ Gal-GFP comprises the first $24 \mathrm{~N}$-terminal residues of $\beta$-galactosidase (Hoskins et al., 2002).

${ }^{c}$ Each $(X)$ sequence of varying length, from 42 to 7 amino acids, comprises residues resulting from the translation of varying portions of the pET24b multicloning site (Hoskins and Wickner, 2006).

GFP fusion proteins were constructed as described in Section Materials and Methods.

GFP-X $\mathrm{X}_{30}-\mathrm{H}_{6}, \mathrm{Hsp} 104$ unfolded GFP-X $\mathrm{X}_{42}-\mathrm{H}_{5}$ at a faster rate than ClpB (Figures 2C,D). However, GFP- $\mathrm{X}_{7}-\mathrm{H}_{6}$ was unfolded faster by $\mathrm{ClpB}$ than $\mathrm{Hsp} 104$, suggesting that Hsp104 may require a longer tag than $\mathrm{ClpB}$, although the difference in unfolding rates may be due to sequence preferences or potential differences in the secondary structure of the tags (Figures 2C,D). We also tested GFP-SsrA, a GFP fusion protein C-terminally tagged with the well-studied SsrA 11-aa peptide, which can be recognized and unfolded by both ClpA and ClpX (Keiler et al., 1996; Singh et al., 2000; Table 1). Both ClpB and Hsp104 unfolded GFP-SsrA at a slow rate, indicating that the SsrA tag is poorly recognized by the two disaggregases (Figures 2C,D). This result is consistent with ClpB having weak binding affinity for the SsrA tag ( $\mathrm{Li}$ et al., 2015) and observations previously reported, but not shown, indicating that $\mathrm{ClpB}$ does not unfold GFP-SsrA (Hinnerwisch et al., 2005). Taken together, ClpB and Hsp104 appear to have substrate preferences for protein unfolding.

We next tested if the rate of protein unfolding of a substrate correlated with the ability of the chaperone to interact stably with the specific substrate. Mutants of $\mathrm{ClpB}$ and Hsp104 with substitutions in the NBD-1 and NBD-2 Walker $\mathrm{B}$ sites $\left(\mathrm{ClpB}_{\mathrm{E} 279 \mathrm{~A}, \mathrm{E} 678 \mathrm{~A} \text { and Hsp104 }}\right.$ E285A,E687A $)$ were used for these experiments because they bind but do not hydrolyze ATP and therefore limit the protein remodeling pathway to substrate interaction (Weibezahn et al., 2003; Bosl et al., 2005).

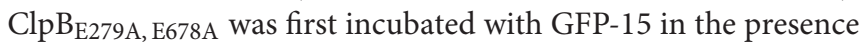
of ATP to allow complex formation. Following incubation, the mixture was subjected to gel filtration chromatography and 
GFP fluorescence was measured in the eluted fractions. We observed a peak of fluorescence eluting near the position of

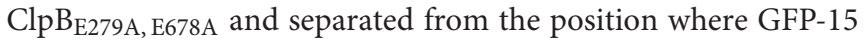
eluted when chromatographed alone (Figures 3A,B). About $27 \pm$ $6 \%$ of the GFP-15 eluted in a complex with ClpB. However, when Hsp104 $2285 \mathrm{~A}$, E687A was incubated with GFP-15 and the mixtures analyzed by gel filtration, there was no detectable peak of GFP15 fluorescence eluting at the position of Hsp104 $\mathrm{E} 285 \mathrm{~A}, \mathrm{E} 687 \mathrm{~A}$ (Figure 3C).

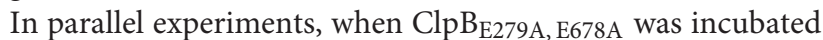
with GFP- $\mathrm{X}_{30}-\mathrm{H}_{6}$ and ATP and analyzed by gel filtration, a single peak of GFP fluorescence was observed that eluted at the position of free GFP- $\mathrm{X}_{30}-\mathrm{H}_{6}$ (Figures 3D,E). In contrast, when Hsp104 $2285 \mathrm{~A}$, E687A was incubated with GFP-X $30-\mathrm{H}_{6}$ and subjected to gel filtration, a peak of fluorescence, which contained
$22 \pm 2 \%$ of the total fluorescence, was detected eluting at the position of Hsp104 (Figure 3F). A third substrate, GFP-X $7-\mathrm{H}_{6}$ was also tested for its ability to interact with $\mathrm{ClpB}_{\mathrm{E} 279 \mathrm{~A}, \mathrm{E} 678 \mathrm{~A} \text { and }}$ Hsp104E285A, E687A via gel filtration analysis (Figures 3G-I). The results were similar to those observed for GFP-15 with about $22 \pm 1 \%$ of the GFP- $\mathrm{X}_{7}-\mathrm{H}_{6}$ eluting in a complex with $\mathrm{ClpB}$ (Figure $3 \mathrm{H}$ ) while there was no detectable complex of GFP-X ${ }_{7}$ $\mathrm{H}_{6}$ and Hsp104 (Figure 3I). Thus, with these three substrates, the results indicate a direct correlation between the rate of substrate unfolding by $\mathrm{ClpB}$ and Hsp104 and the stability of substrate interaction by the chaperone.

To further investigate the relationship between the substrate binding affinity and the rate of substrate unfolding by $\mathrm{ClpB}$ and Hsp104, we monitored the initial rates of unfolding of GFP-X $\mathrm{X}_{30}-\mathrm{H}_{6}, \mathrm{GFP}-\mathrm{X}_{7}-\mathrm{H}_{6}$ and GFP-15, while keeping the

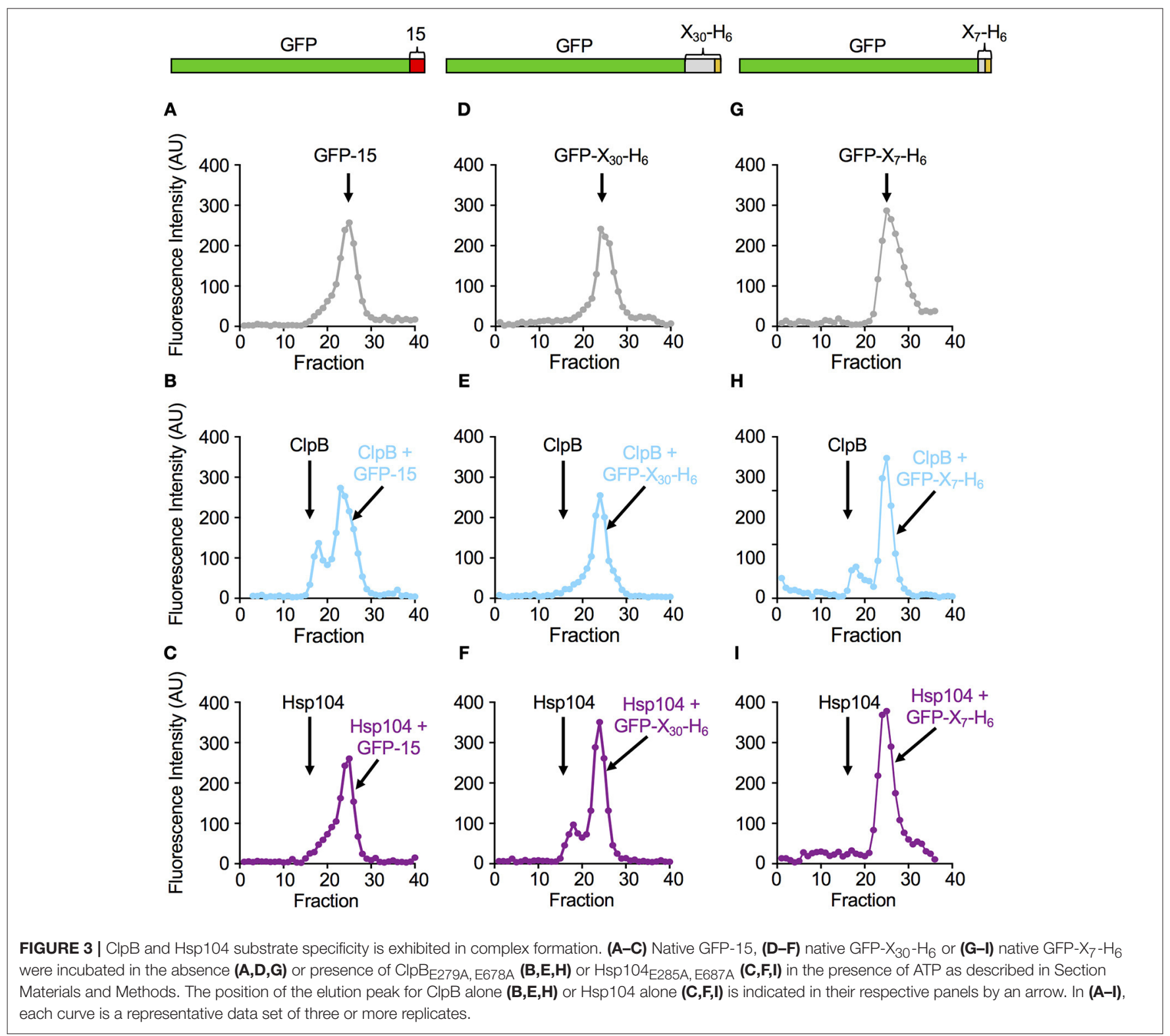


chaperone concentration constant and varying the substrate concentration. For GFP- $\mathrm{X}_{30}-\mathrm{H}_{6}$, Michaelis-Menten analysis indicated that Hsp104 and $\mathrm{ClpB}$ similarly interact with this substrate (Figure 4A). Hsp104 only has an $\sim 2$-fold lower $\mathrm{K}_{\mathrm{M}}$ and less than 2-fold higher $\mathrm{V}_{\max }$ compared to ClpB. GFP-X $\mathrm{X}_{7}-\mathrm{H}_{6}$ was bound similarly by $\mathrm{Hsp} 104$ and $\mathrm{ClpB}$, with $\mathrm{ClpB}$ having less than a 2-fold lower $K_{M}$ for binding than Hsp104 (Figure 4B). However, the maximum unfolding rate $\left(\mathrm{V}_{\max }\right)$ was $\sim 4$-fold higher for ClpB than for Hsp104 with this substrate (Figure 4B). When GFP-15 unfolding was analyzed in the same way, the $\mathrm{K}_{\mathrm{M}}$ for both $\mathrm{ClpB}$ and Hsp104 was the same, however the maximum unfolding rates were again different, with $\mathrm{ClpB}$ having $\sim 3$-fold higher $\mathrm{V}_{\max }$ than Hsp104 with this substrate (Figure 4C). These results indicate that for the substrates tested, binding affinity and the maximum substrate unfolding rate both affect the ability of $\mathrm{ClpB}$ and Hsp104 to efficiently process substrates.

\section{Nucleotide-Binding Domain-1 Is Important for Determining Substrate Binding Specificity}

We wanted to explore substrate discrimination by $\mathrm{ClpB}$ and Hsp104 further by asking what domain or domains of $\mathrm{ClpB}$ and Hsp104 were involved in the substrate discrimination we observed with GFP-15 and GFP- $\mathrm{X}_{30}-\mathrm{H}_{6}$ (Figure 2). For these experiments, we utilized previously characterized chimeras of ClpB and Hsp104 (Miot et al., 2011). The chimeras are designated by a series of four characters that represent the four ClpB/Hsp104 domains from the $\mathrm{N}$ - to C-terminus, the N-domain, NBD-1, Mdomain, and NBD-2 (Figure 5A). "B" represents a domain from $\mathrm{ClpB}$ and " 4 " represents a domain from Hsp104. For example, $444 \mathrm{~B}$ represents the chimera with the N-domain, NBD-1 and M-domain from Hsp104 and NBD-2 from ClpB.

We tested the $\mathrm{ClpB} / \mathrm{Hsp} 104$ chimeras for the ability to discriminate between GFP- $\mathrm{X}_{30}-\mathrm{H}_{6}$ and GFP-15, the two substrates most efficiently unfolded by $\mathrm{Hsp} 104$ and $\mathrm{ClpB}$, respectively (Figures $\mathbf{2 A}, \mathbf{B}$ ). We observed that $\mathrm{B} 4 \mathrm{BB}$, a chimera with NBD-1 from Hsp104 and the other domains from ClpB, unfolded GFP- $\mathrm{X}_{30}-\mathrm{H}_{6}$ at a significantly faster rate than $\mathrm{ClpB}$, although more slowly than Hsp104 wild-type (Figure 5B). This result suggests that the Hsp104 NBD-1 is important for substrate specificity. In support of this suggestion, three other chimeras containing the NBD-1 from Hsp104, B44B, 44B4, and 444B, also unfolded GFP-X $\mathrm{X}_{30}-\mathrm{H}_{6}$ at rates similar to or slightly faster than Hsp104 wild-type (Figure 5B). Additionally, the observation that B44B unfolded GFP- $\mathrm{X}_{30}-\mathrm{H}_{6}$ like Hsp104 wild-type indicates that the N-terminal domain does not affect recognition of GFP-X $\mathrm{X}_{30}$ $\mathrm{H}_{6}$ by $\mathrm{Hsp} 104$ (Figure 5B). 4BBB unfolded $\mathrm{GFP}-\mathrm{X}_{30}-\mathrm{H}_{6}$ at a rate similar to $\mathrm{ClpB}$ wild-type, substantiating the conclusion that NBD-1 plays a role in substrate discrimination with this substrate, but the N-domain does not (Figure 5B).

We next monitored the ability of the chimeras to unfold GFP15, the preferred substrate of ClpB (Figure 2A). As observed for GFP-X $30-\mathrm{H}_{6}$, chimeras with NBD-1 from Hsp104, including B4BB, B44B, 44B4, and 444B, functioned comparably to Hsp104 wild-type and unfolded GFP-15 at a slow rate (Figure 5C). The observation that B44B functioned like Hsp104 wild-type,
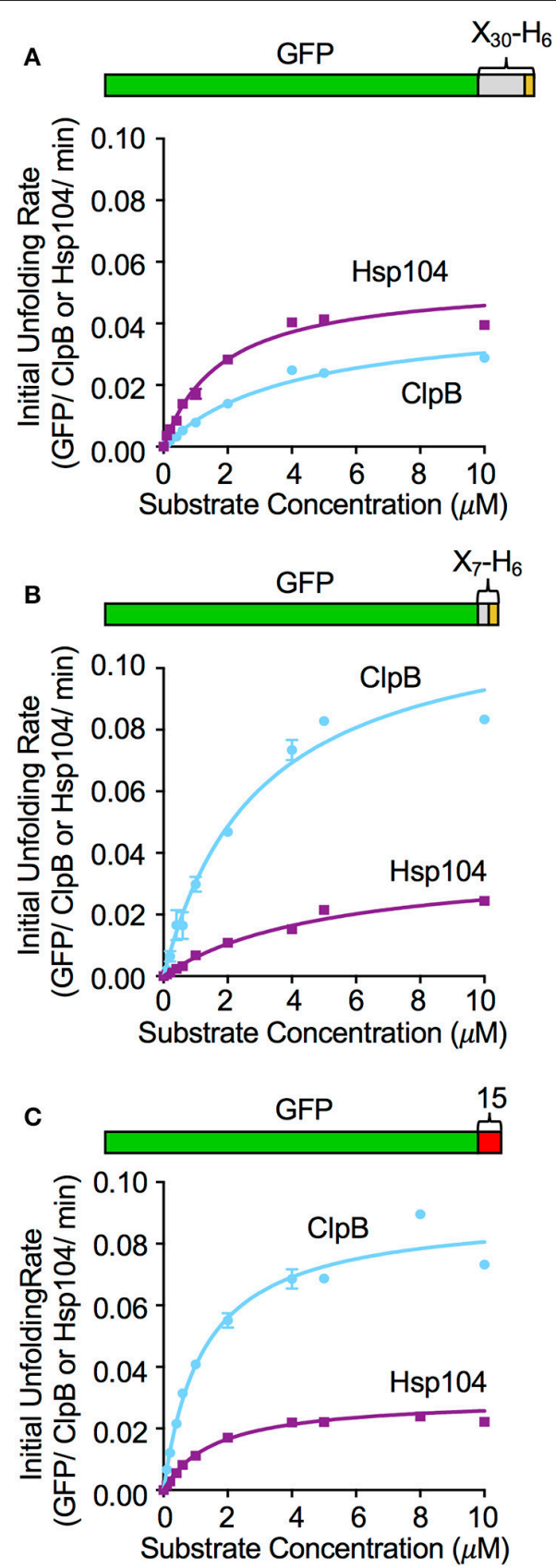

FIGURE 4 | Effect of substrate concentration on the unfolding reaction by $\mathrm{ClpB}$ and $\mathrm{Hsp104}$. The concentration of (A) GFP- $\mathrm{X}_{30}-\mathrm{H}_{6}$, (B) GFP-X $7-\mathrm{H}_{6}$, and (C) GFP-15 was varied in ClpB or Hsp104 mediated unfolding reactions and the initial rate of unfolding was plotted vs. the substrate concentration as described in Section Materials and Methods. Curves shown are the fit of the data to the Michealis-Menten equation and kinetic parameters $\left(K_{M}\right.$ and $\left.V_{\max }\right)$ were determined as described in the Section Materials and Methods. For GFP- $\mathrm{X}_{30}-\mathrm{H}_{6}$ (A) the $\mathrm{Hsp}_{104} \mathrm{~K}_{M}$ and $\mathrm{V}_{\max }$ are $1.8(0.2) \mu \mathrm{M}$ and 0.054 (0.003) $\min ^{-1}$, respectively, while the $\mathrm{ClpB} \mathrm{K}_{\mathrm{M}}$ and $\mathrm{V}_{\max }$ are $4.1(0.4) \mu \mathrm{M}$ and 0.04 (0.002) min $^{-1}$. For GFP- $X_{7}-H_{6}$ (B) the $H_{s p 104} K_{M}$ and $V_{\max }$ are $5.2(0.6) \mu M$ and $0.03(0.001) \mathrm{min}^{-1}$, respectively, while the $\mathrm{ClpB} \mathrm{K}_{M}$ and $V_{\max }$ are 3.0 (0.4) $\mu \mathrm{M}$ and $0.12(0.009) \mathrm{min}^{-1}$. For GFP-15 (C), the Hsp104 $\mathrm{K}_{\mathrm{M}}$ and $\mathrm{V}_{\max }$ are $1.6(0.2) \mu \mathrm{M}$ and $0.03(0.001) \mathrm{min}^{-1}$, respectively, while the $\mathrm{ClpB} \mathrm{K}_{\mathrm{M}}$ and $\mathrm{V}_{\text {max }}$ are $1.2(0.1) \mu \mathrm{M}$ and $0.091(0.003) \mathrm{min}^{-1} . \ln (\mathbf{A}-\mathbf{C})$, data are the means \pm SEM $(n=3)$. 
A

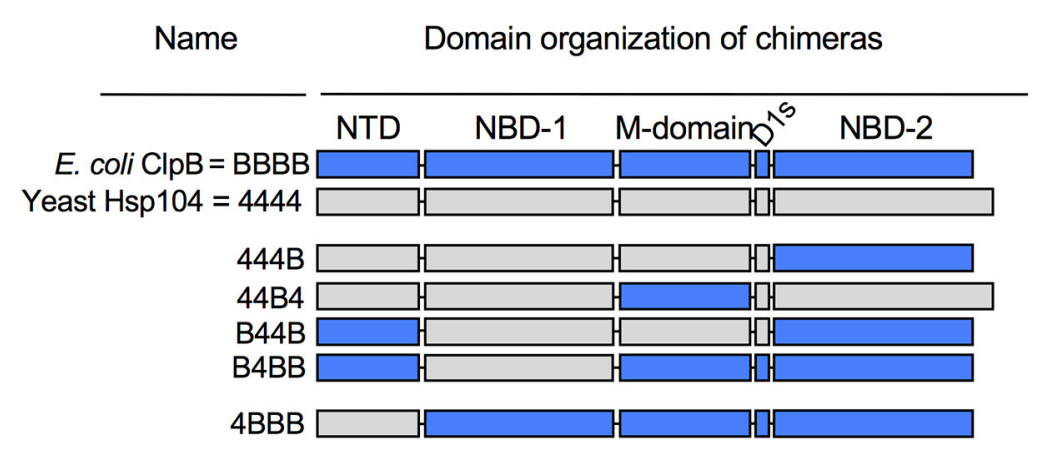

B

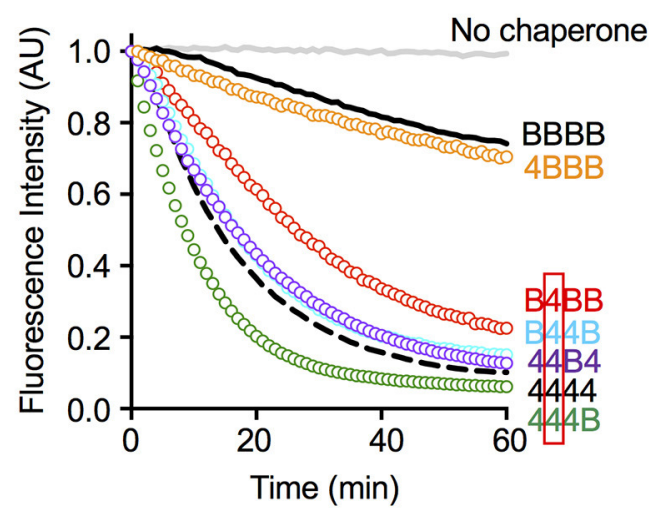

C

GFP-15

FIGURE 5 | Nucleotide-binding domain-1 determines the specificity for substrate in unfolding reactions. (A) Domain organization of the ClpB-Hsp104 chimeras with domains from $\mathrm{ClpB}$ indicated by "B" and shown in blue, and domains derived from Hsp104 indicated by "4" and shown in gray. (B,C) Unfolding of GFP- $\mathbf{X}_{30}-\mathrm{H}_{6}$ (B) or GFP-15 (C) mediated by Hsp104 (4444; dashed black line), ClpB (BBBB; solid black line) or chimeras (colored lines) in the presence of ATP and ATP $\gamma$ S as described in the Section Materials and Methods. The initial fluorescence was set equal to 1 and a data set representative of three or more replicates is shown.

again emphasized that the $\mathrm{N}$-domain is not important for substrate specificity of this substrate (Figure 5C). Additionally, $4 \mathrm{BBB}$, with the N-domain from Hsp104 and NBD-1 from ClpB, unfolded GFP-15 at a rate similar to ClpB wild-type (Figure 5C). Collectively, these results suggest that with the two substrates tested, NBD-1 is important for the substrate unfolding preference of Hsp104 and likely ClpB. Moreover, the N-domain does not appear to be involved in recognition of these substrates by $\mathrm{ClpB}$ and Hsp104.

\section{DISCUSSION}

In this study, we showed that Hsp104 and ClpB, in the absence of Hsp70 or DnaK, exhibit differing substrate preferences. By using chimeras of Hsp104 and ClpB domains we found that Hsp104 NBD-1 largely imparted the substrate specificity of Hsp104. The importance of NBD-1 in substrate binding and translocation has been demonstrated for many Clp/Hsp100 chaperones, including ClpX, ClpA, ClpB, and Hsp104, where it has been found that conserved tyrosines in the channel facing pore loops directly interact with substrates (Lum et al., 2004, 2008; Schlieker et al., 2004; Weibezahn et al., 2004; Hinnerwisch et al., 2005; Martin et al., 2008; Tessarz et al., 2008; Doyle et al., 2012). However, it is not clear what is uniquely different between NBD-1 of Hsp104 and NBD-1 of ClpB that is responsible for the substrate specificity that we observed. The NBD-1 pore loops of Hsp104 and $\mathrm{ClpB}$ are highly conserved suggesting additional residues in NBD-1 are potentially involved in substrate specificity. These additional substrate interactions may be with other residues in the central channel of NBD-1 or with residues in NBD-1 that are transiently exposed due to ATP-dependent conformational changes. Our results are consistent with a previous study by Tipton et al. that used chimeras of Hsp104 and ClpB to show that prion propagation in yeast requires NBD-1 from Hsp 104 and that chimeras with $\mathrm{ClpB}$ NBD-1 were unable to support prion propagation (Tipton et al., 2008). Together, these results suggest that NBD-1 is important for substrate specificity of $\mathrm{ClpB}$ and Hsp104 in the absence of DnaK/Hsp70.

In our unfolding studies, we observed that $\mathrm{ClpB}$ and Hsp104 discriminate between GFP fusion proteins with different polypeptide tags fused at an end. Three of the substrates tested share almost the same $13 \mathrm{C}$-terminal residues, however, ClpB unfolded one $\left(\mathrm{GFP}-\mathrm{X}_{7}-\mathrm{H}_{6}\right)$ at a faster rate than $\mathrm{Hsp} 104$ while Hsp104 unfolded two (GFP-X $30-\mathrm{H}_{6}$ and GFP-X $\mathrm{X}_{42}-\mathrm{H}_{5}$ ) faster than 
ClpB (Figure 2). These results suggest that either the length or the secondary structure of the recognition tag may affect the rate of substrate unfolding. In gel filtration studies monitoring substrate binding to $\mathrm{ClpB}$ and Hsp104, we observed a direct correlation between the rate of substrate unfolding by $\mathrm{ClpB}$ and Hsp104 and the stability of substrate interaction with the chaperone. However, Michaelis-Menten analysis of unfolding assays using three different substrates indicated there was only a 2-fold difference or less in binding affinities between Hsp104 and substrate or $\mathrm{ClpB}$ and substrate. The process of substrate unfolding is comprised of multiple steps including substrate recognition and binding, translocation and release, and the differences observed between $\mathrm{Hsp} 104$ and $\mathrm{ClpB}$ in substrate unfolding are likely due to more than just variances in sequence recognition. Additionally, the stability of the substrate and of the ClpB or Hsp104 hexamer are likely important for the overall substrate unfolding process.

The studies presented here using chimeras of Hsp104 and $\mathrm{ClpB}$ indicate that the $\mathrm{N}$-domain of Hsp104 and ClpB does not affect the substrate discrimination observed with the two substrates tested. Previous studies addressed the role of the $\mathrm{ClpB} \mathrm{N}$-domain in substrate binding and unfolding and showed that the $\mathrm{N}$-domain of $\mathrm{ClpB}$ is important for stabilizing $\mathrm{ClpB}$ and interaction with substrate (Nagy et al., 2010; Doyle et al., 2012; Rosenzweig et al., 2015). It was also shown that the $\mathrm{N}$-domain directly interacts with substrates via a substratebinding groove, and this interaction was nucleotide independent (Rosenzweig et al., 2015). Therefore, substrate interaction with the $\mathrm{N}$-domain is different than the nucleotide-dependent binding observed between substrate and the NBD-1 pore loops (Schlieker et al., 2004; Weibezahn et al., 2004; Zolkiewski, 2006; Lum

\section{REFERENCES}

Baker, T. A., and Sauer, R. T. (2012). ClpXP, an ATP-powered unfolding and protein-degradation machine. Biochim. Biophys. Acta 1823, 15-28. doi: 10.1016/j.bbamcr.2011.06.007

Bosl, B., Grimminger, V., and Walter, S. (2005). Substrate binding to the molecular chaperone Hsp104 and its regulation by nucleotides. J. Biol. Chem. 280, 38170-38176. doi: 10.1074/jbc.M506149200

DeSantis, M. E., Leung, E. H., Sweeny, E. A., Jackrel, M. E., Cushman-Nick, M., Neuhaus-Follini, A., et al. (2012). Operational plasticity enables hsp104 to disaggregate diverse amyloid and nonamyloid clients. Cell 151, 778-793. doi: 10.1016/j.cell.2012.09.038

Diemand, A. V., and Lupas, A. N. (2006). Modeling AAA+ ring complexes from monomeric structures. J. Struct. Biol. 156, 230-243. doi: 10.1016/j.jsb.2006. 04.011

Doyle, S. M., Genest, O., and Wickner, S. (2013). Protein rescue from aggregates by powerful molecular chaperone machines. Nat. Rev. Mol. Cell Biol. 14, 617-629. doi: $10.1038 / \mathrm{nrm} 3660$

Doyle, S. M., Hoskins, J. R., and Wickner, S. (2007a). Collaboration between the ClpB AAA + remodeling protein and the DnaK chaperone system. Proc. Natl. Acad. Sci. U.S.A. 104, 11138-11144. doi: 10.1073/pnas.0703980104

Doyle, S. M., Hoskins, J. R., and Wickner, S. (2012). DnaK chaperone-dependent disaggregation by caseinolytic peptidase $\mathrm{B}(\mathrm{ClpB})$ mutants reveals functional overlap in the N-terminal domain and nucleotide-binding domain-1 pore tyrosine. J. Biol. Chem. 287, 28470-28479. doi: 10.1074/jbc.M112.383091

Doyle, S. M., Shastry, S., Kravats, A. N., Shih, Y. H., Miot, M., Hoskins, J. R., et al. (2015). Interplay between E. coli DnaK, ClpB and GrpE during et al., 2008; Tessarz et al., 2008; Doyle et al., 2012; Rosenzweig et al., 2015). Additionally, previous work indicated that the Ndomains may sterically obstruct access to the central channel and impede substrate binding to the pore loops of NBD-1 (Doyle et al., 2012; Nagy et al., 2010; Rosenzweig et al., 2015). In studies examining the role of the Hsp104 N-domain in protein unfolding and remodeling, it was observed that $\triangle \mathrm{N}$-Hsp 104 was defective in substrate unfolding compared to Hsp104 wildtype, showing a role for the Hsp104 N-domain (Sweeny et al., 2015; Kummer et al., 2016). Therefore, for some substrates it is likely that the $\mathrm{N}$-domain of $\mathrm{ClpB} / \mathrm{Hsp} 104$ is required for stabilizing the initial interaction between chaperone and substrate and thus is required for the subsequent chaperone activity.

Understanding the mechanism of the intrinsic chaperone activity of $\mathrm{ClpB} / \mathrm{Hsp} 104$ is providing the groundwork for understanding the more complex and biologically important reaction carried out by $\mathrm{ClpB} / \mathrm{Hsp} 104$ in physical and functional collaboration with DnaK/Hsp70.

\section{AUTHOR CONTRIBUTIONS}

DJ, MM, JH, SW, and SD designed the experiments. DJ, MM, JH, and SD performed the experiments. All authors were involved in data interpretation and discussion. SW and SD wrote the manuscript with contributions from $\mathrm{JH}$.

\section{FUNDING}

This research was supported by the Intramural Research Program of the NIH, NCI, Center for Cancer Research. protein disaggregation. J. Mol. Biol. 427, 312-327. doi: 10.1016/j.jmb.2014. 10.013

Doyle, S. M., Shorter, J., Zolkiewski, M., Hoskins, J. R., Lindquist, S., and Wickner, S. (2007b). Asymmetric deceleration of ClpB or Hsp104 ATPase activity unleashes protein-remodeling activity. Nat. Struct. Mol. Biol. 14, 114-122. doi: 10.1038/nsmb1198

Erzberger, J. P., and Berger, J. M. (2006). Evolutionary relationships and structural mechanisms of AAAt proteins. Annu. Rev. Biophys. Biomol. Struct. 35, 93-114. doi: 10.1146/annurev.biophys.35.040405. 101933

Flynn, J. M., Neher, S. B., Kim, Y. I., Sauer, R. T., and Baker, T. A. (2003). Proteomic discovery of cellular substrates of the ClpXP protease reveals five classes of ClpX-recognition signals. Mol. Cell 11, 671-683. doi: 10.1016/S1097-2765(03)00060-1

Glover, J. R., and Lindquist, S. (1998). Hsp104, Hsp70, and Hsp40: a novel chaperone system that rescues previously aggregated proteins. Cell 94, 73-82. doi: $10.1016 /$ S0092-8674(00)81223-4

Glover, J. R., and Lum, R. (2009). Remodeling of protein aggregates by Hsp104. Protein Pept. Lett. 16, 587-597. doi: 10.2174/092986609788490087

Glover, J. R., Kowal, A. S., Schirmer, E. C., Patino, M. M., Liu, J. J., and Lindquist, S. (1997). Self-seeded fibers formed by Sup35, the protein determinant of [PSI+], a heritable prion-like factor of S. cerevisiae. Cell 89, 811-819. doi: 10.1016/S0092-8674(00)80264-0

Goloubinoff, P., Mogk, A., Zvi, A. P., Tomoyasu, T., and Bukau, B. (1999). Sequential mechanism of solubilization and refolding of stable protein aggregates by a bichaperone network. Proc. Natl. Acad. Sci. U.S.A. 96, 13732-13737. doi: 10.1073/pnas.96.24.13732 
Guo, F., Maurizi, M. R., Esser, L., and Xia, D. (2002). Crystal structure of ClpA, an Hsp100 chaperone and regulator of ClpAP protease. J. Biol. Chem. 277, 46743-46752. doi: 10.1074/jbc.M207796200

Hanson, P. I., and Whiteheart, S. W. (2005). AAA+ proteins: have engine, will work. Nat. Rev. Mol. Cell Biol. 6, 519-529. doi: 10.1038/nrm1684

Heuck, A., Schitter-Sollner, S., Suskiewicz, M. J., Kurzbauer, R., Kley, J., Schleiffer, A., et al. (2016). Structural basis for the disaggregase activity and regulation of Hsp104. Elife 5:e21516. doi: 10.7554/eLife.21516

Hinnerwisch, J., Reid, B. G., Fenton, W. A., and Horwich, A. L. (2005). Roles of the $\mathrm{N}$-domains of the ClpA unfoldase in binding substrate proteins and in stable complex formation with the ClpP protease. J. Biol. Chem. 280, 40838-40844. doi: 10.1074/jbc.M507879200

Hodson, S., Marshall, J. J., and Burston, S. G. (2012). Mapping the road to recovery: the ClpB/Hsp104 molecular chaperone. J. Struct. Biol. 179, 161-171. doi: 10.1016/j.jsb.2012.05.015

Hoskins, J. R., and Wickner, S. (2006). Two peptide sequences can function cooperatively to facilitate binding and unfolding by ClpA and degradation by ClpAP. Proc. Natl. Acad. Sci. U.S.A. 103, 909-914. doi: 10.1073/pnas.0509154103

Hoskins, J. R., Doyle, S. M., and Wickner, S. (2009). Coupling ATP utilization to protein remodeling by $\mathrm{ClpB}$, a hexameric AAA+ protein. Proc. Natl. Acad. Sci. U.S.A. 106, 22233-22238. doi: 10.1073/pnas.0911937106

Hoskins, J. R., Kim, S. Y., and Wickner, S. (2000). Substrate recognition by the ClpA chaperone component of ClpAP protease. J. Biol. Chem. 275, 35361-35367. doi: 10.1074/jbc.M006288200

Hoskins, J. R., Yanagihara, K., Mizuuchi, K., and Wickner, S. (2002). ClpAP and ClpXP degrade proteins with tags located in the interior of the primary sequence. Proc. Natl. Acad. Sci. U.S.A. 99, 11037-11042. doi: $10.1073 /$ pnas. 172378899

Inoue, Y., Taguchi, H., Kishimoto, A., and Yoshida, M. (2004). Hsp104 binds to yeast Sup35 prion fiber but needs other factor(s) to sever it. J. Biol. Chem. 279, 52319-52323. doi: 10.1074/jbc.M408159200

Keiler, K. C., Waller, P. R., and Sauer, R. T. (1996). Role of a peptide tagging system in degradation of proteins synthesized from damaged messenger RNA. Science 271, 990-993. doi: 10.1126/science.271.5251.990

Krzewska, J., and Melki, R. (2006). Molecular chaperones and the assembly of the prion Sup35p, an in vitro study. EMBO J. 25, 822-833. doi: 10.1038/sj.emboj.7600985

Kummer, E., Szlachcic, A., Franke, K. B., Ungelenk, S., Bukau, B., and Mogk, A. (2016). Bacterial and yeast AAA+ disaggregases $\mathrm{ClpB}$ and Hsp104 operate through conserved mechanism involving cooperation with Hsp70. J. Mol. Biol. 428, 4378-4391. doi: 10.1016/j.jmb.2016.09.003

Lee, S., Choi, J. M., and Tsai, F. T. (2007). Visualizing the ATPase cycle in a protein disaggregating machine: structural basis for substrate binding by ClpB. Mol. Cell 25, 261-271. doi: 10.1016/j.molcel.2007.01.002

Lee, S., Sielaff, B., Lee, J., and Tsai, F. T. (2010). CryoEM structure of Hsp104 and its mechanistic implication for protein disaggregation. Proc. Natl. Acad. Sci. U.S.A. 107, 8135-8140. doi: 10.1073/pnas.1003572107

Lee, S., Sowa, M. E., Watanabe, Y. H., Sigler, P. B., Chiu, W., Yoshida, M., et al. (2003). The structure of $\mathrm{ClpB}$ : a molecular chaperone that rescues proteins from an aggregated state. Cell 115, 229-240. doi: 10.1016/S0092-8674(03)0 $0807-9$

Li, T., Lin, J., and Lucius, A. L. (2015). Examination of polypeptide substrate specificity for Escherichia coli ClpB. Proteins 83, 117-134. doi: 10.1002/prot. 24710

Lum, R., Niggemann, M., and Glover, J. R. (2008). Peptide and protein binding in the axial channel of Hsp104. Insights into the mechanism of protein unfolding. J. Biol. Chem. 283, 30139-30150. doi: 10.1074/jbc.M804849200

Lum, R., Tkach, J. M., Vierling, E., and Glover, J. R. (2004). Evidence for an unfolding/threading mechanism for protein disaggregation by Saccharomyces cerevisiae Hsp104. J. Biol. Chem. 279, 29139-29146. doi: $10.1074 /$ jbc.M403777200

Mackay, R. G., Helsen, C. W., Tkach, J. M., and Glover, J. R. (2008). The C-terminal extension of Saccharomyces cerevisiae Hsp104 plays a role in oligomer assembly. Biochemistry 47, 1918-1927. doi: 10.1021/bi701714s

Martin, A., Baker, T. A., and Sauer, R. T. (2008). Pore loops of the AAA+ ClpX machine grip substrates to drive translocation and unfolding. Nat. Struct. Mol. Biol. 15, 1147-1151. doi: 10.1038/nsmb.1503
Miot, M., Reidy, M., Doyle, S. M., Hoskins, J. R., Johnston, D. M., Genest, O., et al. (2011). Species-specific collaboration of heat shock proteins (Hsp) 70 and 100 in thermotolerance and protein disaggregation. Proc. Natl. Acad. Sci. U.S.A. 108, 6915-6920. doi: 10.1073/pnas.1102828108

Mogk, A., Kummer, E., and Bukau, B. (2015). Cooperation of Hsp70 and Hsp100 chaperone machines in protein disaggregation. Front. Mol. Biosci. 2:22. doi: 10.3389/fmolb.2015.00022

Motohashi, K., Watanabe, Y., Yohda, M., and Yoshida, M. (1999). Heat-inactivated proteins are rescued by the DnaK.J-GrpE set and ClpB chaperones. Proc. Natl. Acad. Sci. U.S.A. 96, 7184-7189. doi: 10.1073/pnas.96.13.7184

Nagy, M., Guenther, I., Akoyev, V., Barnett, M. E., Zavodszky, M. I., Kedzierska-Mieszkowska, S., et al. (2010). Synergistic cooperation between two ClpB isoforms in aggregate reactivation. J. Mol. Biol. 396, 697-707. doi: $10.1016 /$ j.jmb.2009.11.059

Reidy, M., Sharma, R., Shastry, S., Roberts, B. L., Albino-Flores, I., Wickner, S., et al. (2014). Hsp40s specify functions of Hsp104 and Hsp90 protein chaperone machines. PLoS Genet. 10:e1004720. doi: 10.1371/journal.pgen.1004720

Romanova, N. V., and Chernoff, Y. O. (2009). Hsp104 and prion propagation. Protein Pept. Lett. 16, 598-605. doi: 10.2174/092986609788490078

Rosenzweig, R., Farber, P., Velyvis, A., Rennella, E., Latham, M. P., and Kay, L. E. (2015). ClpB N-terminal domain plays a regulatory role in protein disaggregation. Proc. Natl. Acad. Sci. U.S.A. 112, E6872-E6881. doi: $10.1073 /$ pnas. 1512783112

Rosenzweig, R., Moradi, S., Zarrine-Afsar, A., Glover, J. R., and Kay, L. E. (2013). Unraveling the mechanism of protein disaggregation through a ClpB-DnaK interaction. Science 339, 1080-1083. doi: 10.1126/science.1233066

Savistchenko, J., Krzewska, J., Fay, N., and Melki, R. (2008). Molecular chaperones and the assembly of the prion Ure2p in vitro. J. Biol. Chem. 283, 15732-15739. doi: $10.1074 /$ jbc.M800728200

Schlieker, C., Weibezahn, J., Patzelt, H., Tessarz, P., Strub, C., Zeth, K., et al. (2004). Substrate recognition by the AAA+ chaperone ClpB. Nat. Struct. Mol. Biol. 11, 607-615. doi: 10.1038/nsmb787

Seyffer, F., Kummer, E., Oguchi, Y., Winkler, J., Kumar, M., Zahn, R., et al. (2012). Hsp70 proteins bind Hsp100 regulatory M domains to activate AAA+ disaggregase at aggregate surfaces. Nat. Struct. Mol. Biol. 19, 1347-1355. doi: $10.1038 / \mathrm{nsmb} .2442$

Shorter, J., and Lindquist, S. (2004). Hsp104 catalyzes formation and elimination of self-replicating Sup35 prion conformers. Science 304, 1793-1797. doi: $10.1126 /$ science. 1098007

Shorter, J., and Lindquist, S. (2006). Destruction or potentiation of different prions catalyzed by similar Hsp104 remodeling activities. Mol. Cell 23, 425-438. doi: 10.1016/j.molcel.2006.05.042

Siddiqui, S. M., Sauer, R. T., and Baker, T. A. (2004). Role of the processing pore of the ClpX AAA+ ATPase in the recognition and engagement of specific protein substrates. Genes Dev. 18, 369-374. doi: 10.1101/gad.1170304

Sielaff, B., and Tsai, F. T. (2010). The M-domain controls Hsp104 protein remodeling activity in an Hsp70/Hsp40-dependent manner. J. Mol. Biol. 402, 30-37. doi: 10.1016/j.jmb.2010.07.030

Singh, S. K., Grimaud, R., Hoskins, J. R., Wickner, S., and Maurizi, M. R. (2000). Unfolding and internalization of proteins by the ATP-dependent proteases ClpXP and ClpAP. Proc. Natl. Acad. Sci. U.S.A. 97, 8898-8903. doi: 10.1073/pnas.97.16.8898

Sweeny, E. A., Jackrel, M. E., Go, M. S., Sochor, M. A., Razzo, B. M., DeSantis, M. E., et al. (2015). The hsp104 N-terminal domain enables disaggregase plasticity and potentiation. Mol. Cell 57, 836-849. doi: 10.1016/j.molcel.2014.12.021

Tessarz, P., Mogk, A., and Bukau, B. (2008). Substrate threading through the central pore of the Hsp104 chaperone as a common mechanism for protein disaggregation and prion propagation. Mol. Microbiol. 68, 87-97. doi: $10.1111 / j .1365-2958.2008 .06135 . x$

Tipton, K. A., Verges, K. J., and Weissman, J. S. (2008). In vivo monitoring of the prion replication cycle reveals a critical role for Sis1 in delivering substrates to Hsp104. Mol. Cell 32, 584-591. doi: 10.1016/j.molcel.2008.11.003

Tuite, M. F., Marchante, R., and Kushnirov, V. (2011). Fungal prions: structure, function and propagation. Top. Curr. Chem. 305, 257-298. doi: 10.1007/128_2011_172

Weber-Ban, E. U., Reid, B. G., Miranker, A. D., and Horwich, A. L. (1999). Global unfolding of a substrate protein by the Hsp100 chaperone ClpA. Nature 401, 90-93. doi: $10.1038 / 43481$ 
Weibezahn, J., Schlieker, C., Bukau, B., and Mogk, A. (2003). Characterization of a trap mutant of the AAA+ chaperone ClpB. J. Biol. Chem. 278, 32608-32617. doi: $10.1074 /$ jbc.M303653200

Weibezahn, J., Tessarz, P., Schlieker, C., Zahn, R., Maglica, Z., Lee, S., et al. (2004). Thermotolerance requires refolding of aggregated proteins by substrate translocation through the central pore of ClpB. Cell 119, 653-665. doi: 10.1016/j.cell.2004.11.027

Wendler, P., Ciniawsky, S., Kock, M., and Kube, S. (2012). Structure and function of the AAA+ nucleotide binding pocket. Biochim. Biophys. Acta 1823, 2-14. doi: 10.1016/j.bbamcr.2011.06.014

Wickner, R. B., Edskes, H. K., Bateman, D., Kelly, A. C., and Gorkovskiy, A. (2011). The yeast prions [PSI+] and [URE3] are molecular degenerative diseases. Prion 5, 258-262. doi: 10.4161/pri.17748

Winkler, J., Tyedmers, J., Bukau, B., and Mogk, A. (2012). Chaperone networks in protein disaggregation and prion propagation. J. Struct. Biol. 179, 152-160. doi: 10.1016/j.jsb.2012.05.002

Yokom, A. L., Gates, S. N., Jackrel, M. E., Mack, K. L., Su, M., Shorter, J., et al. (2016). Spiral architecture of the Hsp104 disaggregase reveals the basis for polypeptide translocation. Nat. Struct. Mol. Biol. 23, 830-837. doi: $10.1038 / \mathrm{nsmb} .3277$

Zhang, T., Ploetz, E. A., Nagy, M., Doyle, S. M., Wickner, S., Smith, P. E., et al. (2012). Flexible connection of the N-terminal domain in $\mathrm{ClpB}$ modulates substrate binding and the aggregate reactivation efficiency. Proteins 80, 2758-2768. doi: 10.1002/prot. 24159

Zolkiewski, M. (1999). ClpB cooperates with DnaK, DnaJ, and GrpE in suppressing protein aggregation. A novel multi-chaperone system from Escherichia coli. J. Biol. Chem. 274, 28083-28086. doi: 10.1074/jbc.274.40.28083

Zolkiewski, M. (2006). A camel passes through the eye of a needle: protein unfolding activity of Clp ATPases. Mol. Microbiol. 61, 1094-1100. doi: 10.1111/j.1365-2958.2006.05309.x

Zolkiewski, M., Zhang, T., and Nagy, M. (2012). Aggregate reactivation mediated by the Hsp100 chaperones. Arch. Biochem. Biophys. 520, 1-6. doi: 10.1016/j.abb.2012.01.012

Conflict of Interest Statement: The authors declare that the research was conducted in the absence of any commercial or financial relationships that could be construed as a potential conflict of interest.

Copyright (c) 2017 Johnston, Miot, Hoskins, Wickner and Doyle. This is an openaccess article distributed under the terms of the Creative Commons Attribution License (CC BY). The use, distribution or reproduction in other forums is permitted, provided the original author(s) or licensor are credited and that the original publication in this journal is cited, in accordance with accepted academic practice. No use, distribution or reproduction is permitted which does not comply with these terms. 